\title{
Augmented Reality Dalam Visualisasi Katalog Penjualan Toko Aneka Furniture Berbasis Android Menggunakan Algoritma Fast Corner Detection
}

\author{
Krisna Syahira Wibowo ${ }^{1, *}$, Fauziah $^{2}$ Ira Diana Sholihati $^{3}$ \\ ${ }^{1,2,3)}$ Universitas Nasional, Jl. Sawo Manila, Pejaten Ps. Minggu Jakarta 12520 \\ Informatika, Fakultas Teknologi Komunikasi dan Informatika \\ e-mail : ${ }^{* 1}$ krisnasyahirawibowo50@ gmail.com, ${ }^{2}$ fauziah@ civitas.unas.ac.id, \\ 3iradiana2803@gmail.com
}

\begin{abstract}
Abstrak
Bisnis furniture memiliki peluang keberhasilan yang menjanjikan. Di karenakan bisnis ini memiliki daya beli dan kebutuhan yang cukup tinggi. Sehingga dibutuhkan inovasi dalam menarik daya beli para konsumen. Promosi menjadi salah satu faktor yang penting dalam berlangsungnya sebuah bisnis. Saat ini proses promosi toko-toko furniture banyak menggunakan katalog penjualan. Maka dari itu perlu dilakukannya inovasi dalam mempromosikan barang niaga yang akan dipasarkan. Karena semakin berkembangnya teknologi, maka diusulkannya penerapan strategi dengan menggunakan teknologi augmented reality yang diimplementasikan kedalam aplikasi berbasis android dengan metode marker based tracking dan menggunakan beberapa algoritma untuk di bandingkan yaitu algoritma Fast Corner Detection. Dengan marker yang dijalankan melalui aplikasi android dan masing-masing marker meтuat gambar furniture yang akan dideteksi. Setelah dideteksi, maka akan muncul objek 3 dimensi diatas marker tersebut. Selain itu, detail furniture akan nampak lebih hidup dan nyata. Dengan begitu, diharapkan dapat memberi inovasi dan daya tarik bagi para pelanggan yang akan membeli. Penelitian ini menghasilkan aplikasi android sebagai alat promosi dalam pemasaran produk Toko Aneka Furniture agar lebih interaktif. Implementasi AR menggunakan algoritma FAST Corner Detection sangat membantu dalam memperinci suatu produk yang ingin dipasarkan oleh perusahaan melalui objek $3 D$ untuk lebih menarik minat daya beli konsumen Toko Aneka Furniture.
\end{abstract}

Keywords: FAST Corner Detection, Augmented Reality, Furniture, Inovasi, Smartphone Android.

Abstract
The furniture business has the promised chance of success. This is because this business has a high enough purchasing power and needs. So it takes innovation in attracting the purchasing power of consumers. Promotion is one of the most important factors in running a business. Currently, the promotion process for furniture stores uses a lot of sales catalogs. Therefore, innovation is needed in promoting commercial goods to be marketed. Due to the development of technology, it is proposed to apply a strategy using augmented reality technology which is implemented into an android-based application with a marker based tracking method and uses several algorithms to compare, namely the Fast Corner Detection algorithm. With markers that are run through the android application and each marker contains an image of the furniture to be detected. Once detected, a 3-dimensional object will appear above the marker. In addition, the details of the furniture will look more alive and real. That way, it is expected to provide innovation and attraction for customers who will buy. This research produces an android application as a promotional tool in the marketing of the Aneka Furniture Store products to make it more interactive. AR implementation using the FAST Corner Detection algorithm is very helpful in detailing a product that will be marketed by the company through $3 D$ objects to attract more buying interest from Aneka Furniture Store consumers. 
Kata kunci: FAST Corner Detection, Augmented Reality, Furniture, Innovations, Android Smartphones.

\section{PENDAHULUAN}

Furniture atau mebel adalah suatu produk yang di gunakan pada rumah dan kantor. Produk tersebut yang berbahan dasar dari material logam, kayu, plastik, dll. Produk furniture yang sering ditemukan beberapa tempat, seperti di rumah, dikantor, dan dihotel. Calon pembeli biasanya banyak mencari produk seperti: buffet, lemari cabbinet, tempat tidur, kursi gaming, lemari TV [1]. Seiring waktu perkembangan teknologi informasi semakin pesat. Dan semakin ketatnya persaingan bisnis bagi para pengusaha berusaha untuk mencoba menarik konsumen dengan berbagai media promosi. Terlihat bahwa banyak perusahaan yang memanfaatkan promosi dengan cara memanfaatkan perkembangan teknologi di era milenial ini. Banyaknya industri perusahaan mewajibkan setiap perusahaan untuk lebih berani berinovasi dan mempromosikan hasil produknya pada konsumennya, supaya konsumen lebih paham dan mengerti produk yang sesuai dengan apa yang ingin dibeli. Masing-masing perusahaan diharuskan memilki daya tarik dan stratetgi yang lebih inovatif dan modern. Salah satunya memanfaatkan Teknologi Augmented Reality (AR) yang bertujuan agar pelanggan dapat lebih mengetahui tentang informasi produk lebih rinci. Karena banyak dari konsumen, ketika ingin membeli produk belum mengetahui bentuk asli dan nyata seperti apa, karena media yang digunakan masih dalam bentuk katalog gambar dua dimensi, yang hanya bisa dilihat dari satu arah saja [2]. Toko Aneka Furniture merupakan sebuah usaha yang bergerak dibidang furniture seperti; perabot rumah tangga, perkantoran dan juga industri. Kualitas yang didijual Toko Aneka Furniture sangat baik. Maka dibutuhkan inovasi dan ide agar menambah daya tarik pelanggan. Dengan begitu, media promosi menjadi sesuatu hal menarik agar para konsumen dapat tertarik dengan apa yang di tawarkan atau dipromosikan. Maka tercetuslah media promosi menggunakan visualisasi 3 dimensi (3D) agar lebih menambah daya tarik konsumen melihat detail produk yang akan dibeli atau digunakan. Sistem operasi yang digunakan adalah android. Android dipilih karena sistem operasi tersebut banyak digunakan pada saat ini, dan mudah untuk diakses dimanapun dan kapanpun. Pengguna smartphone juga telah banyak menjamah ke kalangan masyarakat. Dan diharapkan, aplikasi yang digunakan tidak terlalu sulit untuk masyarakat, yang menjadi tugas akhir penulis. Topik ini diangkat karena dibutuhkannya inovasi dalam mempromosikan produk yang akan dijual agar memiliki daya pikat tersendiri.

Pada penelitian terdahulu meneliti tentang Augmented Reality dengan judul "Penerapan Teknologi Augmented Reality Pada Katalog Mebel Kompas Jati Jepara Berbasis Android". Augmented Reality (AR) merupakan teknologi informasi digital yang digunakan secara realtime [3]. Penelitian sebelumnya dengan judul "Penerapan Teknologi Augmented Reality Sebagai media Promosi Berbasis Android Pada Toko Jati Tresno". Yang juga memanfaatkan teknologi AR sebagai media promosi [4]. Kemudian peneliti terdahulu dengan judul "Augmented Reality Katalog Penjualan IT Hardware Pada PT. Unibless Menggunakan Algoritma MSER (Maximally Stable Extermal Regions)" [5]. Pada bagian ini penulis menggunakan metode marker based tracking, karena refrensi penelti terdahulu dengan judul "Implementasi Augmented Reality Furniture Dengan User-Defined Target Berbasis Android" [6]. Penelitian ini juga menggunakan metode Algoritma FAST Corner Detection yang diterapkan pada penelitian sebelumnya yang berjudul "Augmented Reality Marker Based Tracking Visualisasi Drawing 2D ke dalam Bentuk 3D dengan Metode FAST Corner Detection". Terdapat pendeteksian data pada objek yang ditargetkan sebagai acuan target manajer [7]. 


\section{METODE PENELITIAN}

\subsection{Flowchart Aplikasi}

Pada gambar 1 merupakan rancangan Aplikasi AR Katalog Penjualan Furniture untuk media promosi penjualan Toko Aneka Furniture.

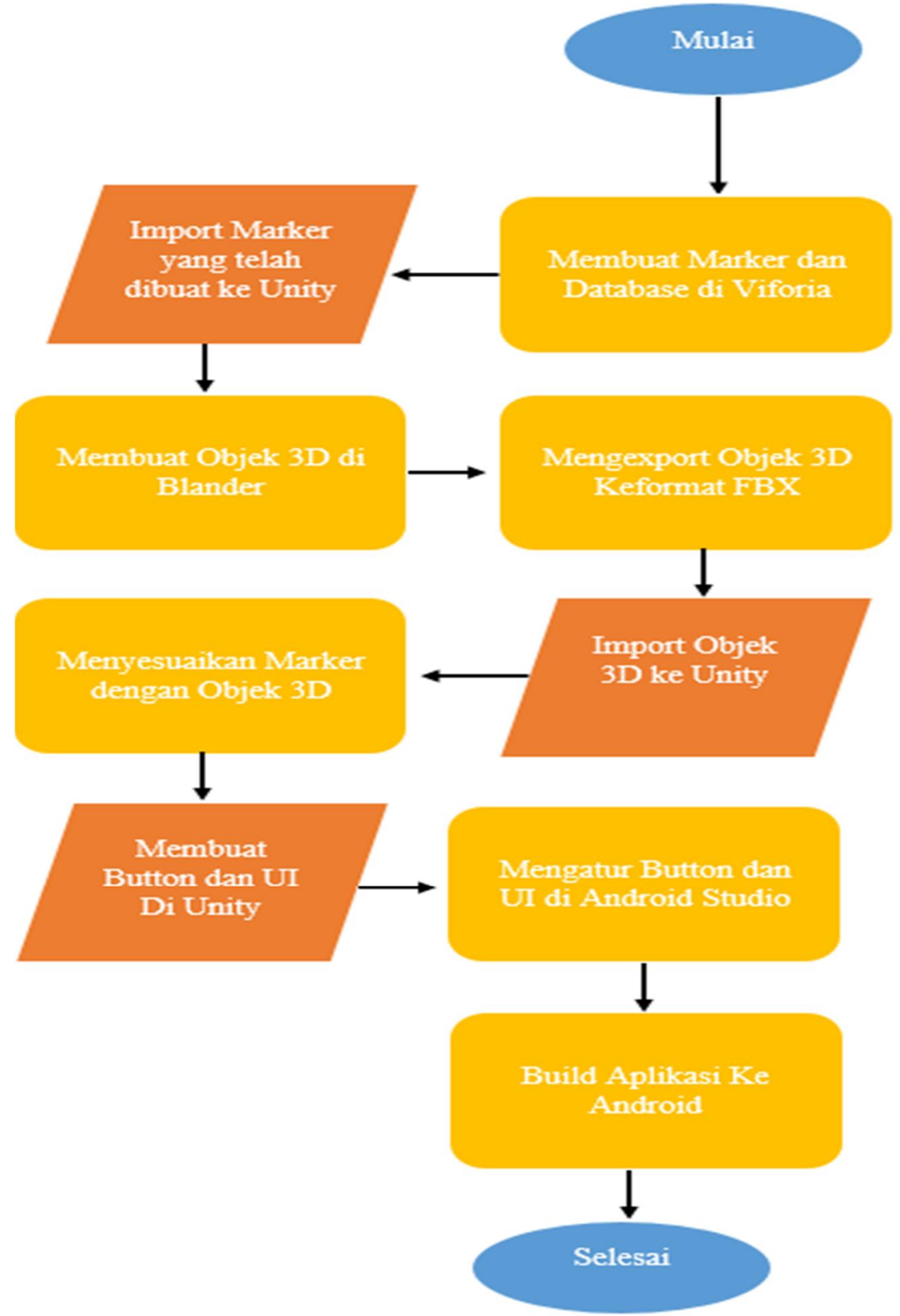

Gambar 1. Flowchart Perancangan Aplikasi AR

Flowchart merupakan sebuah bagan yang menunjukan alur rencana dari keseluruhan sistem. Perancangan dimulai dari tahap pembuatan marker, lalu berlanjut ke pada pembuatan objek 3D dengan aplikasi Blender, lalu ekspor objek 3D ke format .FBX lalu import objek

Krisna, et., al [Augmented Reality Dalam Visualisasi Katalog Penjualan Toko Aneka Furniture Berbasis Android Menggunakan Algoritma Fast Corner Detection] 
tersebut ke aplikasi Unity, berlanjut dengan membuat Button pada aplikasi Unity dan disesuaikan diaplikasi Android Studio, dan terakhir build aplikasi ke android.

\subsection{Marker Based Tracking}

Dalam augmented Reality ada dua pendeteksi target, yaitu dengan marker dan tanpa marker (markerless). Marker adalah suatu pola unik yang mampu diterima melalui kamera yang bertujuan agar aplikasi AR mengenali pola unik untuk ditampilkan menjadi sebuah objek 3D. Foto atau gambar buatan dengan pola unik dapat dijadikan sebagai marker. Cara kerja marker dengan memanfaatkan teknik pengenalan tanda atau fiducial marker. Marker adalah suatu metode pelacakan, yang mana AR dengan objek di dunia nyata sebagai marker. Teknik yang digunakan adalah prinsip deteksi tepi, yang mendeteksi sudut dan tekstur dari objek atau gambar [8]. Dalam pengembangan teknoligi augmented reality, marker Based Tracking adalah metode yang digunakan. Cara kerja metode marker based tracking adalah dengan cara mengidentifikasi dan mendeteksi pola pada suatu marker. Marker terdiri dari pola atau gambar tertentu berwarna hitam dan putih berbentuk persegi dengan sisi hitam lebih dominan [9]. Marker juga digunakan sebagai penanda khusus bertujuan agar dikenali oleh AR kamera untuk dapat menampilkan objek 3D sesuai dengan kebutuhan. Dan akan terwujud dunia virtual 3D dari hasil deteksi orientasi dan posisi marker yang dilakukan oleh AR kamera. Pada gambar 2 adalah contoh marker.

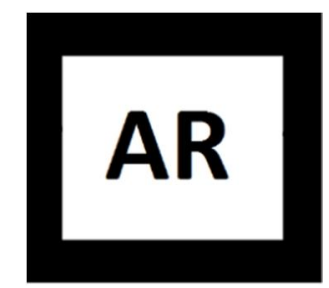

Gambar 2. Contoh Marker

Marker memiliki titik atau poin koordinat untuk menentukan letak posisi dari tampilan objek 3D pada ruang nyata. Marker terletak sejajar dengan posisi dari objek 3D. Objek 3D berdiri simetris dengan sumbu Z, serta tegak lurus dengan sumbu Y (depan dan belakang) dan sumbu X (kanan dan kiri) dari poin koordinat marker. Pada gambar 3 merupakan contoh marker dengan poin koordinat

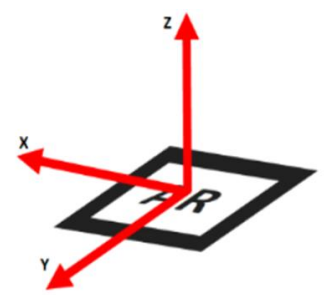

Gambar 3. Poin Marker Dengan Poin Koordinat

Untuk penerapan metode Marker based tarcking dibutuhkan software yaitu Vuforia. Software tersebut bekerja dengan menjadikan marker sebagai database untuk di import ke aplikasi Unity. Lalu database akan dipanggil melalui AR Camera yang ada pada Unity. Dan akan mendeteksi marker menjadi sebuah objek 3D. Pada penelitian ini menggunakan marker based tracking, dan berikut contoh implepentasi terlihat pada gambar 4. 


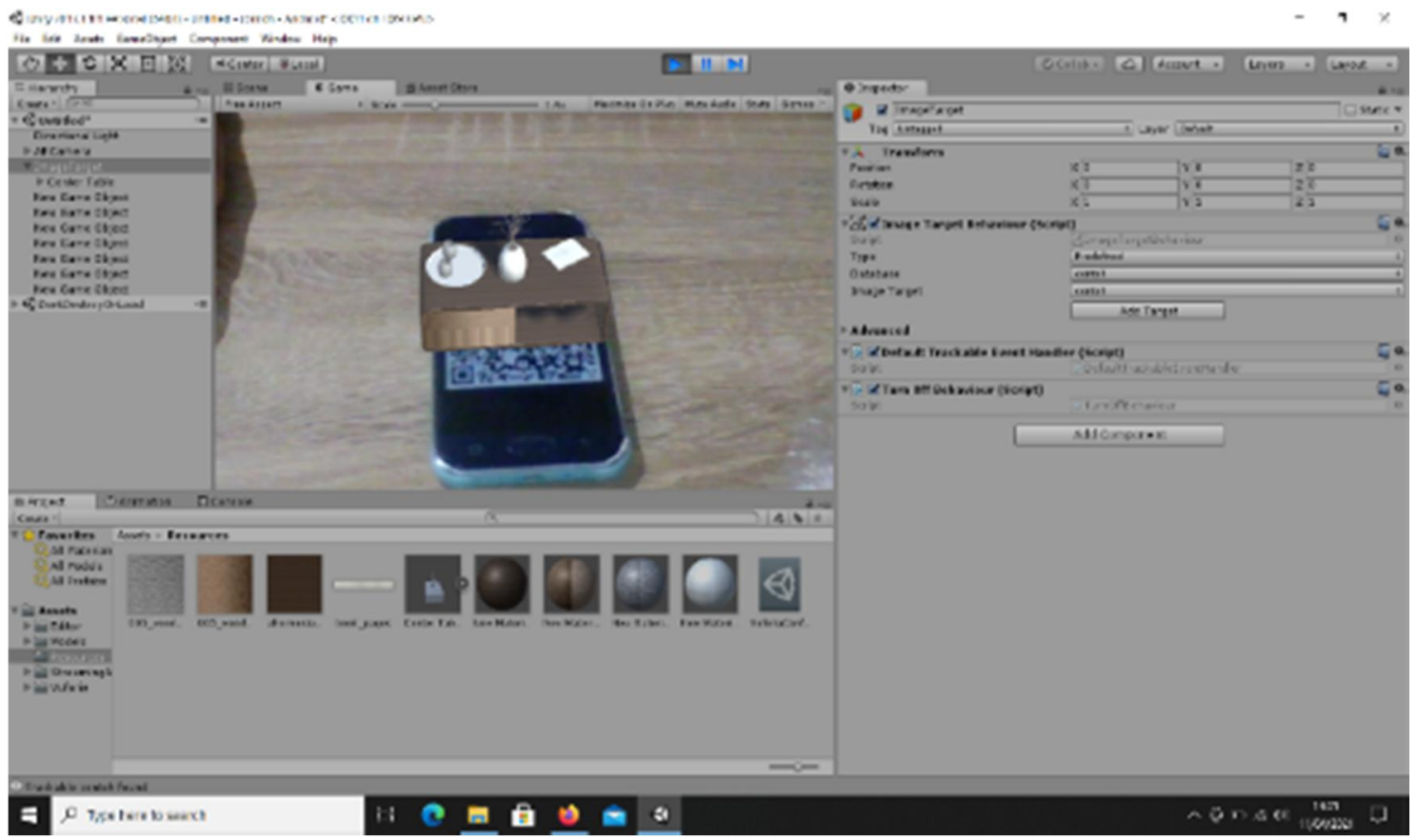

Gambar 4. Implementasi AR Menggunakan Marker Based Tracking

\subsection{Algoritma Fast Corner}

FAST Corner atau Features from Accelerated Segment Test merupakan suatu teknik dalam objek 2D melalui sudut-sudut objek yang menggunakan tingkat kecerahan pada objek. Digunakan nilai khusus untuk mendeteksi pendekatan yang digunakan untuk nilai khusus dari suatu objek seperti deteksi dan sisi bentuk. Sudut adalah titik dominan kebalikan dari arah titik tersebut, yang merupakan haluan antara dua sisi atau edge. Algoritma Fast Corner Detection adalah sebagai berikut :

1) Salah satu titik $p$ dipilih yang merupakan titik pertama piksel tengah.

2) Radius lingkungan yang dipilih sebagai 3 pixel.

3) Yang diibaratkan sebagai p1, p2 dan p16 adalah pixel aktif yang diberi nomor yang sesuai arah jarum jam.

4) Kemudian pada keempat koordinat disekelilingnya bandingkan sesuai intensitas titik pusat $p$, titik pusat $p$ adalah bila terdapat 3 titik koordinat memenuhi, maka titik pusat $p$ adalah titik sudut. [10]

Salah satu tahap untuk proses mendeteksi marker adalah menggunakan algoritma Fasr Corner Detection pada saat memproses gambar yang diunggah kedalam Vuforia. Objek akan ditentukan dari suatu gambar, algoritma menghasilkan poin koordinat yang akan dikenali dan disesuaikan dengan perlemgkapan gambar pada AR kamera. Koordinat yang telah dihasilkan pada algoritma akan menentukan keunikan pada objek yang telah dimasukkan. Marker akan mempengaruhi suatu tingkat nilai atau rating pada gambar yang telah digunakan sebagai marker. Algoritma juga akan mempengaruhi tampilan dan tingkat kemunculan sebuah objek 3D melalui pengenalan deteksi sudut. [11] 


\section{HASIL DAN PEMBAHASAN}

\subsection{Tampilan Marker pada Katalog Aneka Furniture}

Marker adalah suatu penanda atau pola yang biasa digunakan pada augmented reality untuk melacak suatu titik atau wilayah. Photoshop CS6 sebagai aplikasi yang digunakan untuk mendesain pola marker. Marker berupa barcode yang dapat di scan pada katalog penjualan barang seperti pada gambar 5 .

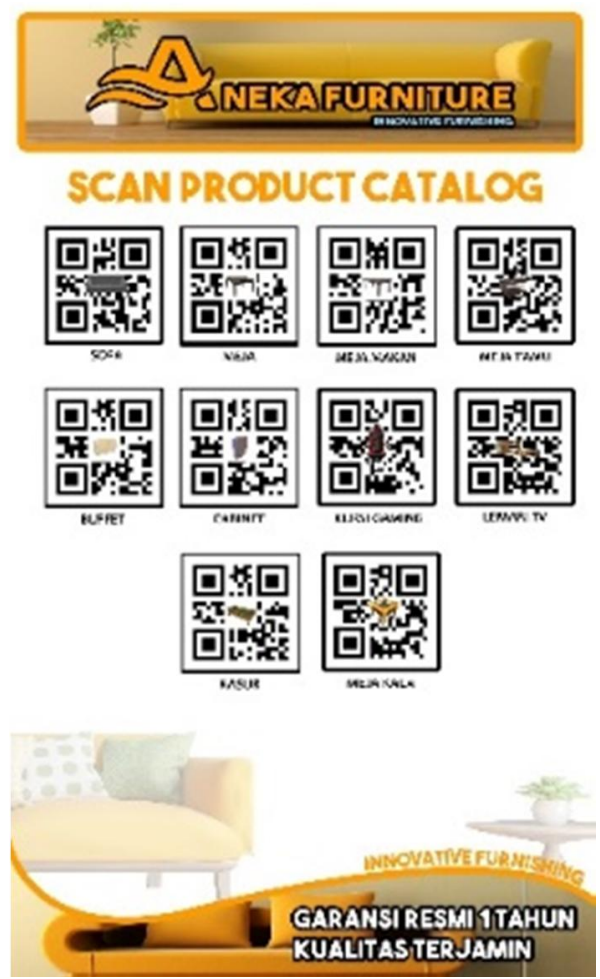

Gambar 5. Katalog Penjualan

Pada katalog penjualan terdapat beberapa produk yang dipasarkan, diantaranya:

1) Meja

2) Meja Makan

3) Sofa

4) Meja Tamu

5) Bufet

6) Cabinet

7) Kursi Gaming

8) Lemari TV

9) Kasur

10) Meja Kaca

Pada tabel 1 adalah marker yang telah diinput dalam database Vuvoria engine. Citra yang dapat dikenali menggunakan algoritma yang digunakan untuk mendeteksi marker pada augmented reality adalah FAST Corner Detection, yang mana algoritma tersebut telah tersedia pada library Vuforia engine, berfungsi untuk mendeteksi fitur-fitur yang ada pada gambar yang sudah dipilih. Kemudian dari gambar yang telah terdeteksi, akan dinilai dari kualitas atau resolusi gambar tersebut untuk menentukan tingkat kualitas gambar yang dapat terdeteksi dan

Krisna, et., al [Augmented Reality Dalam Visualisasi Katalog Penjualan Toko Aneka Furniture Berbasis Android Menggunakan Algoritma Fast Corner Detection] 
terlacak menggunakan Vuforia engine, dengan interval nilai 0 sampai 5, dengan nilai terendah 0 dan nilai tertinggi 5.

Tabel 1. Rating yang Terdapat pada Vuvoria

\begin{tabular}{llc}
\hline No. & Marker & Rating \\
\hline 1. & & \\
& &
\end{tabular}

2.

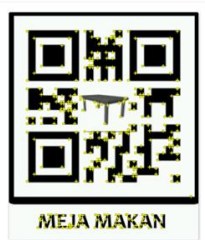

3.

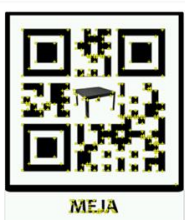

4.

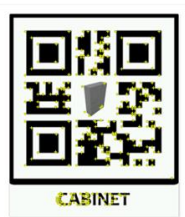

5.
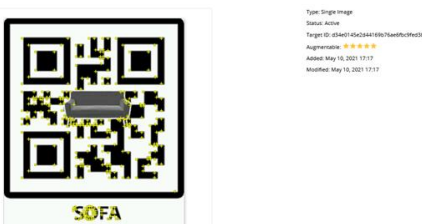

5

6
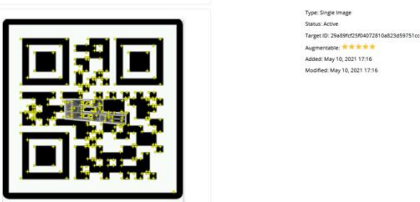

LEMARI TV

7.
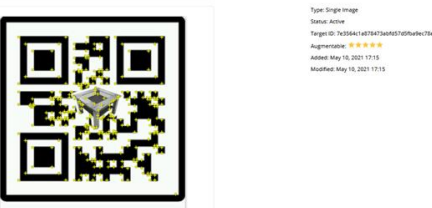

5

MEIAKACA 
8.

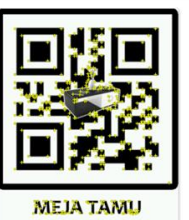

9.

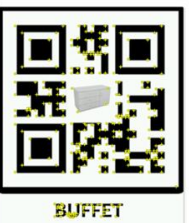

10.
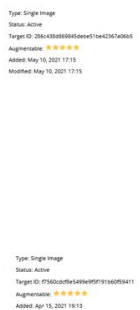

5

5

5

$=-5$

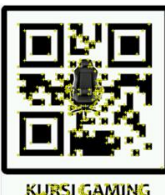

5

\subsection{Implementasi Algoritma FAST Corner pada AR Kamera}

Dengan presisi yang baik dari titik-titik sudut yang terekstrasi dengan perhitungan yang tinggi dan effisien. Proses tersebut sering digunakan pada pendeteksian objek untuk menentukan suatu objek dari bentuk objek dan pelacakan suatu objek. [12] Contoh penerapan algoritma FAST Corner adalah sebagai berikut :

1) Yang terlebih dahulu ditentukan adalah citra dengan posisi pertama ( $x p, y p)$ pada koordinat $p$

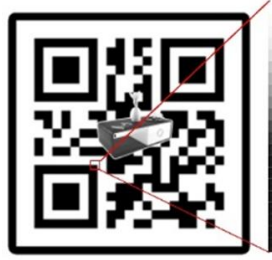

Gambar 6. Titik Koordinat Awal (Menentukan Titik P)

2) Menentukan koordinat 16 titik Pixel radius dengan tiga pixel dari titik $p$
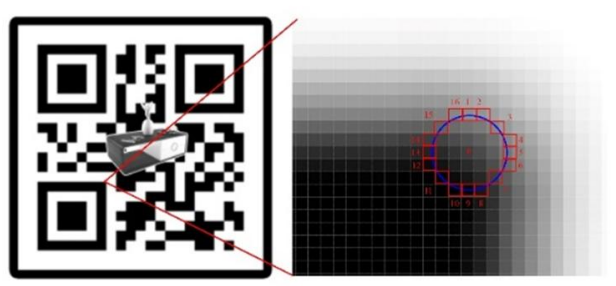

Gambar 7. Titik Koordinat Awal (Menentukan Titik $P$ )

3) 4 titik dari 16 pixel ditentukan. Titik pertama adalah $(\mathrm{n}=3)$ koordinat $\left(x_{p}, y_{p+3}\right)$, titik kedua adalah $(\mathrm{n}=2)$ koordinat $\left(y_{p+3}, x_{p}\right)$, titik ketiga adalah $(\mathrm{n}=3)$ koordinat $\left(\mathrm{x}_{\mathrm{p}}, \mathrm{y}_{\mathrm{p}-3}\right)$, titik keempat adalah $(\mathrm{n}=2)$ koordinat $\left(x_{p-3}, y_{p}\right)$, seperti pada gambar 8 . 

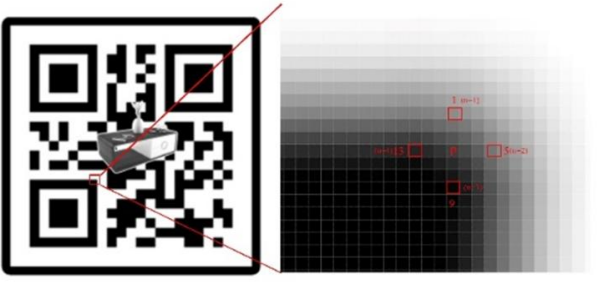

Gambar 8. Titik $P$ Pada 4 Koordinat

4) Perbandingan intensitas poin pusat $p$ dengan keempat titik sudut jika terdapat tiga titik memenuhi tiga kategori yang ditetapkan dalam algoritma Fast Corner adalah :

$$
S_{p \rightarrow x}=\left\{\begin{array}{lrrrr}
d, & & I_{p \rightarrow x} \leq I_{p}-t & (\text { Gelap }) \\
s, & I_{p}-t< & I_{p \rightarrow x}<I_{p}+t & (\text { Normal }) \\
b, & I_{p}+t \leq & I_{p \rightarrow x} & & \text { (Cerah) }
\end{array}\right.
$$

Keterangan :

$\mathrm{Sp} \rightarrow \mathrm{x}:$ Intesitas poin pusat (poin $\mathrm{p}$ )

Ip $\rightarrow \mathrm{x}:$ Intesitas piksel $\mathrm{x}$ (poin intesitas tetangga ke-n)

T : Threshold

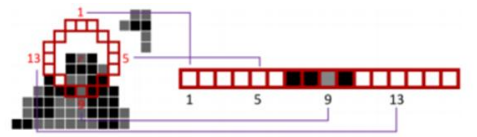

Gambar 9. Intensitas 16 pixel dari titik $p$

5) Implementasi Algoritma Fast Corner dapat digambarkan pada flowchart berikut: 


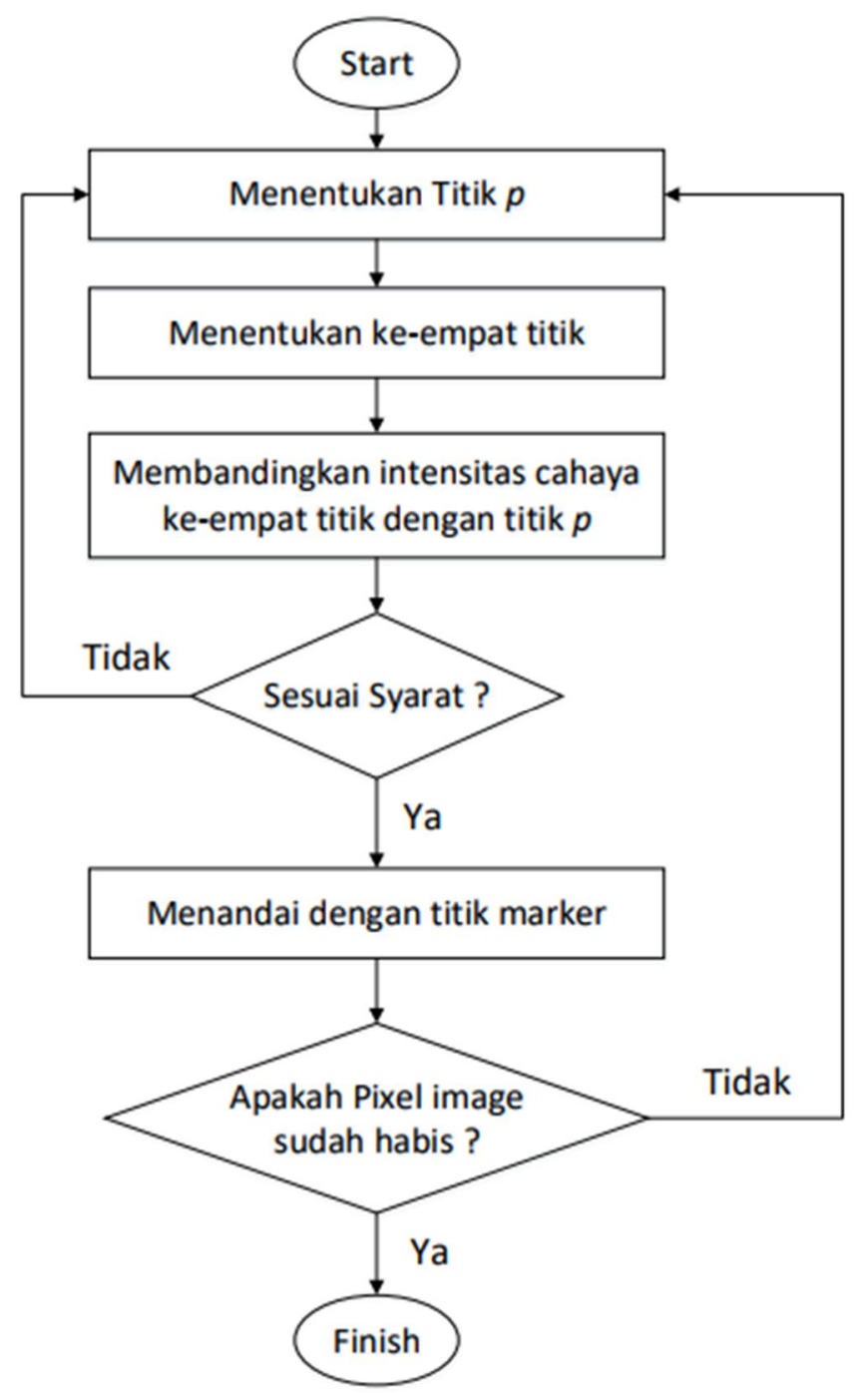

Gambar 10. Alur Diagram Fast Corner Detection

\subsection{Desain GUI (Graphic User Interface)}

Perancangan aplikasi merupakan hal terpenting dalam sebuah interface, agar tampilan aplikasi lebih menarik. Berikut ini adalah tampilan interface pada aplikasi AR Toko Aneka Furniture.

1) Menu Utama

Tampilan menu terdiri dari tiga button gambar. Yang pertama button untuk masuk kedalam menu product, yang kedua kedalam menu about atau tentang perusahaan, dan yang ketiga untuk keluar atau exit. 


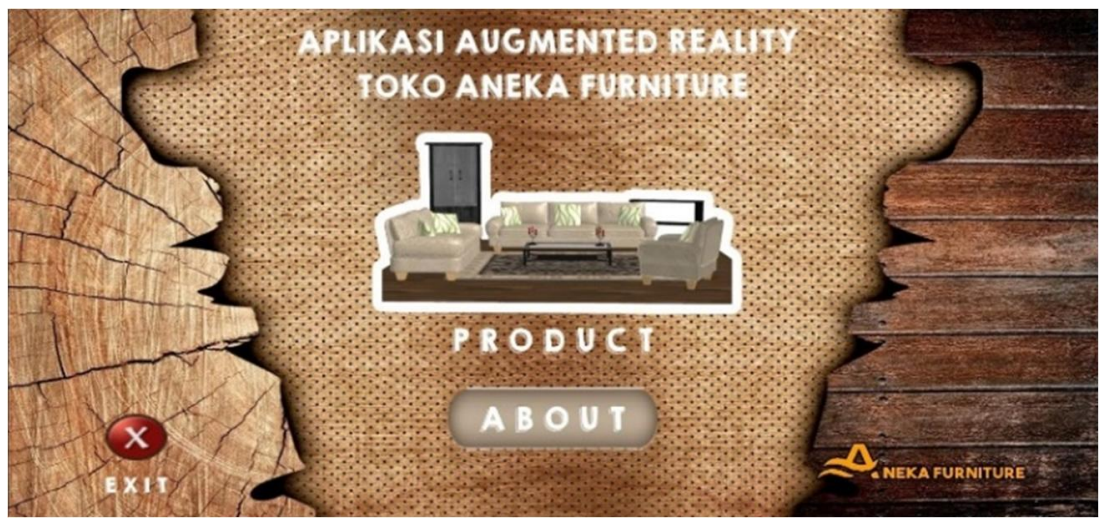

Gambar 11. Tampilan Menu Utama

2) Menu About

Pada tampilan about menjabarkan tentang perusahaan dan cara menggunakan aplikasi tersebut.

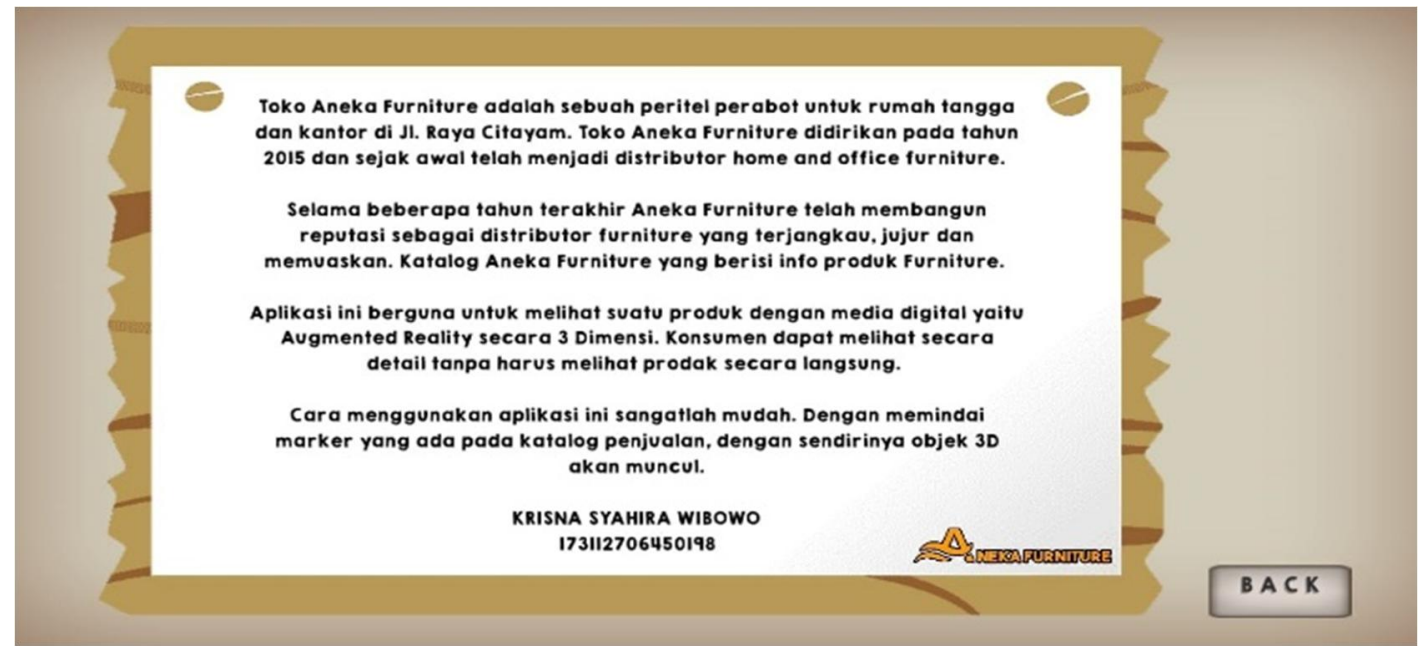

Gambar 12. Tampilan Menu About

\section{3) Menu Product}

Tampilan produk terdapat beberapa button gambar pilihan untuk memunculkan Augmented Reality pada produk katalog. 


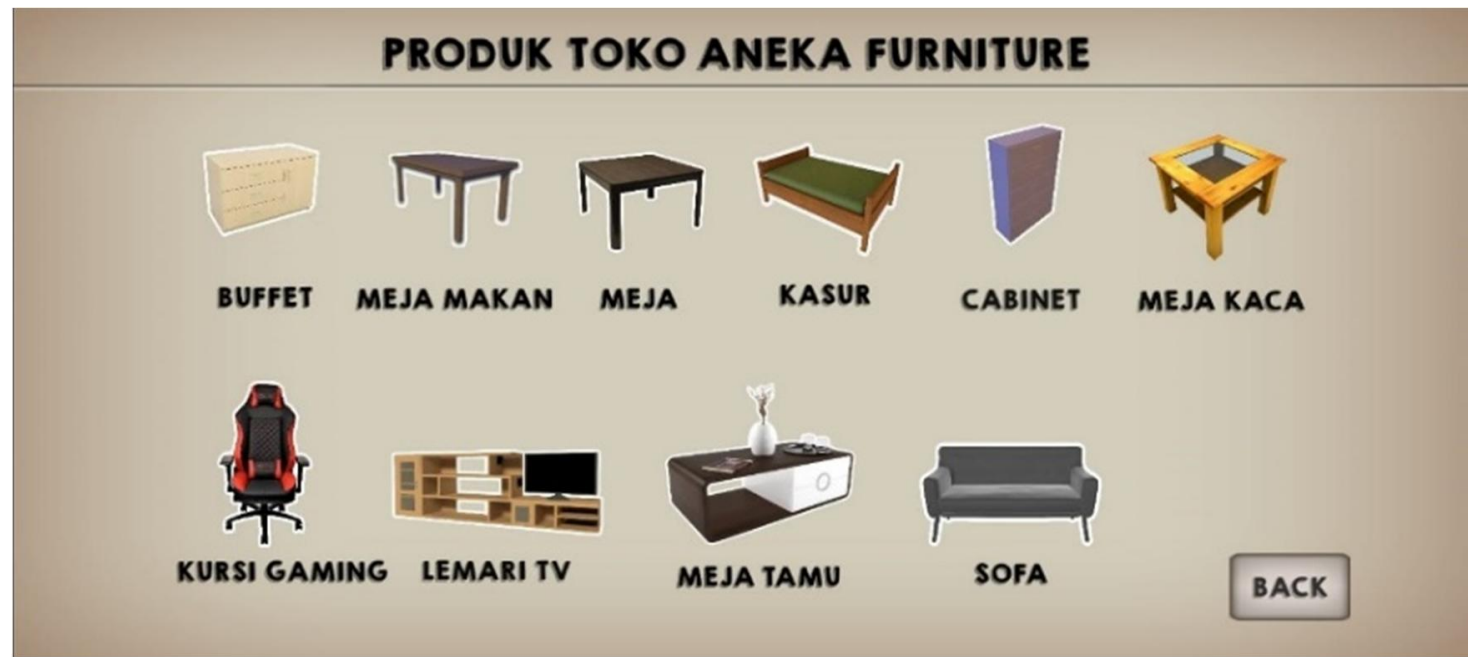

Gambar 13. Menu Product

4) Menampilkan Objek

Pilih produk yang ingin ditampilkan, maka aplikasi akan menampilkan kamera untuk mendeteksi marker yang akan memunculkan objek 3D, informasi dan harga produk yang telah dipilih pada menu.

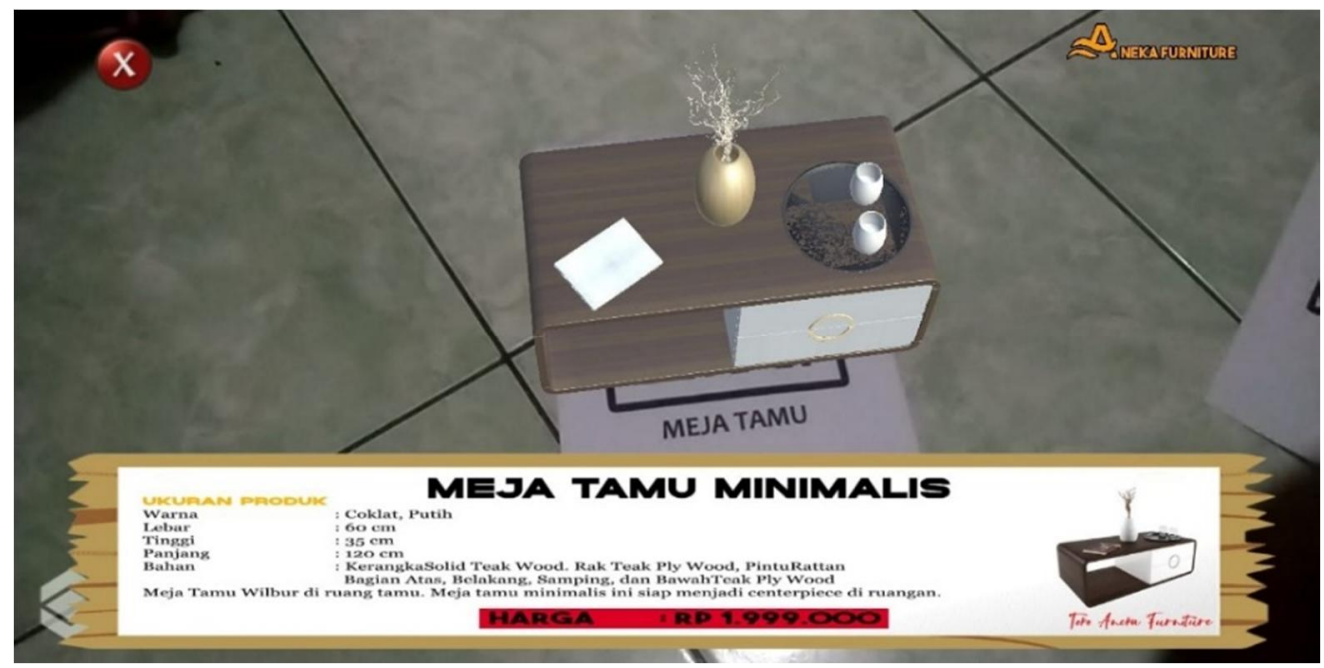

Gambar 14. Tampilan Objek Meja Tamu 


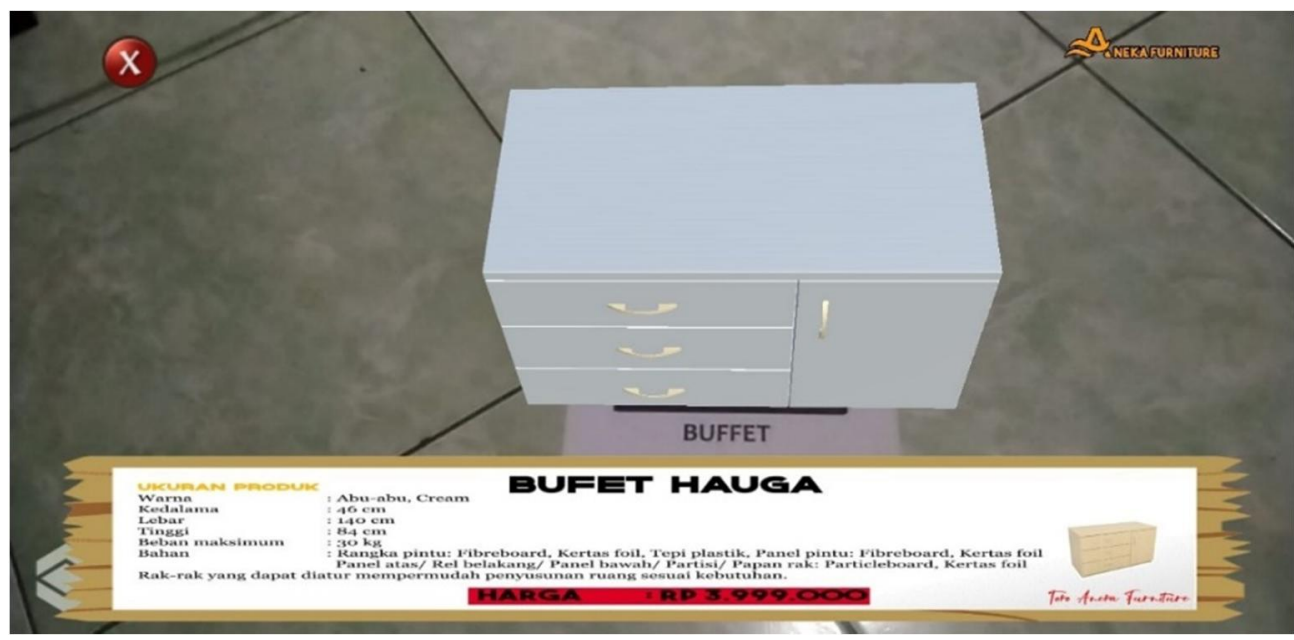

Gambar 15. Tampilan Objek Bufet

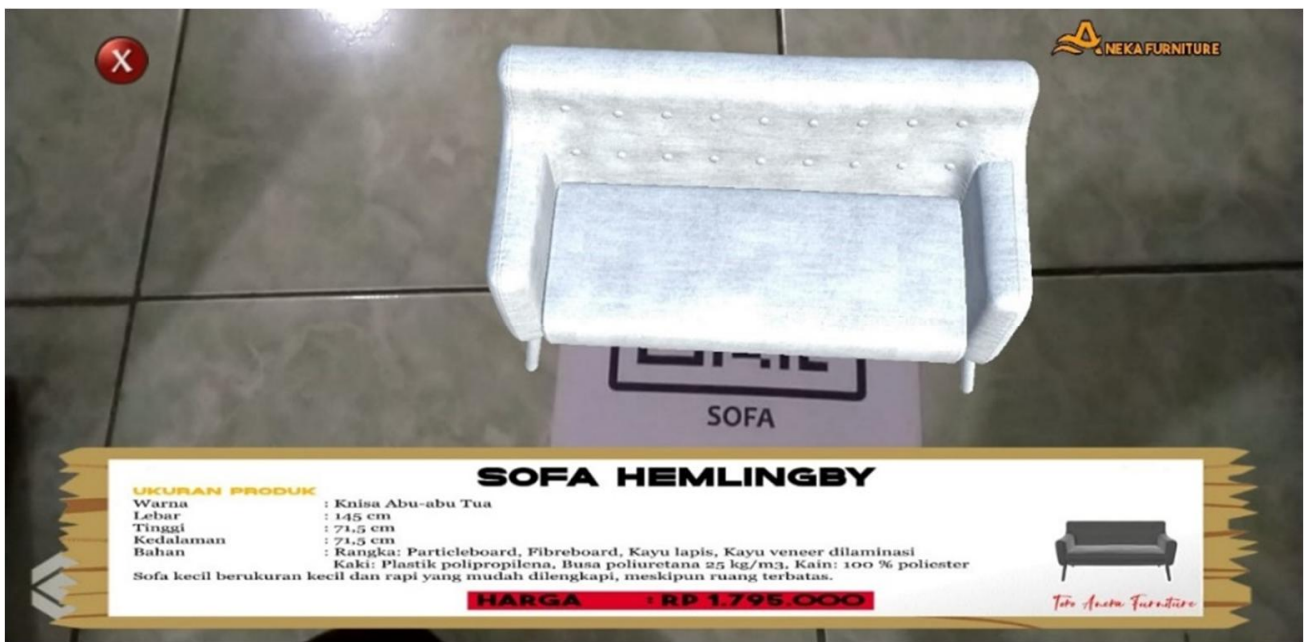

Gambar 16. Tampilan Objek Sofa

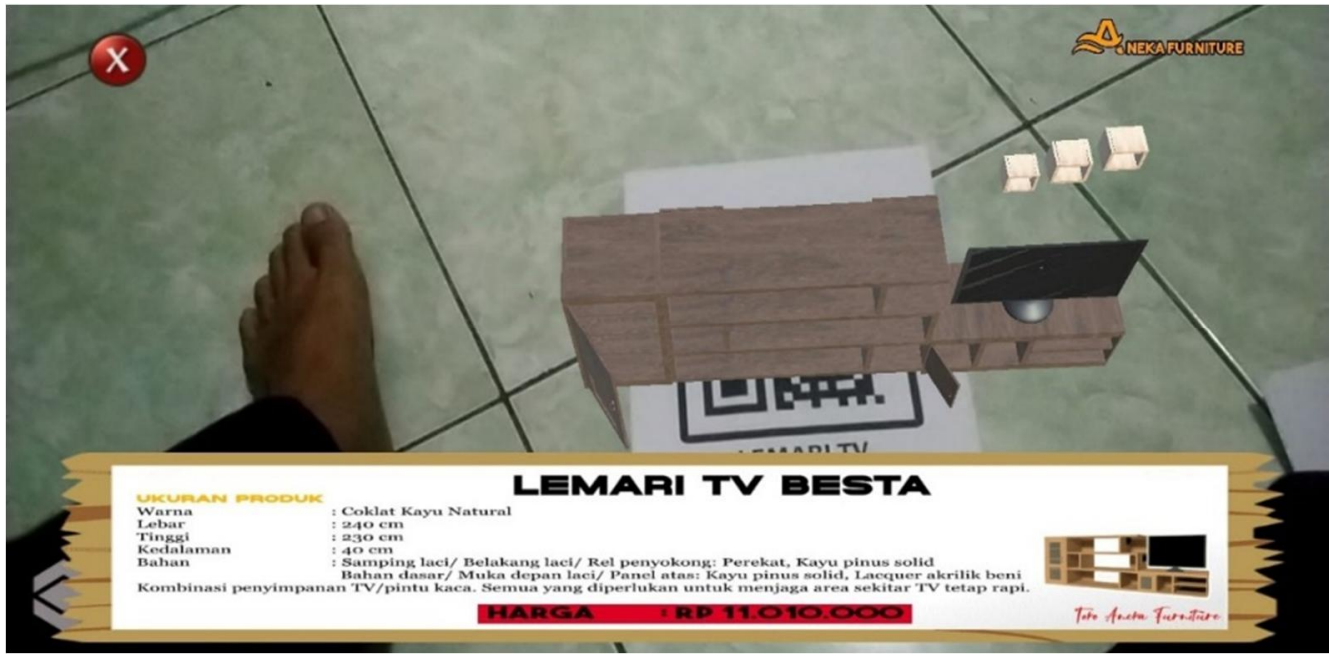

Gambar 17. Tampilan Objek Lemari TV

Krisna, et., al [Augmented Reality Dalam Visualisasi Katalog Penjualan Toko Aneka Furniture Berbasis Android Menggunakan Algoritma Fast Corner Detection] 


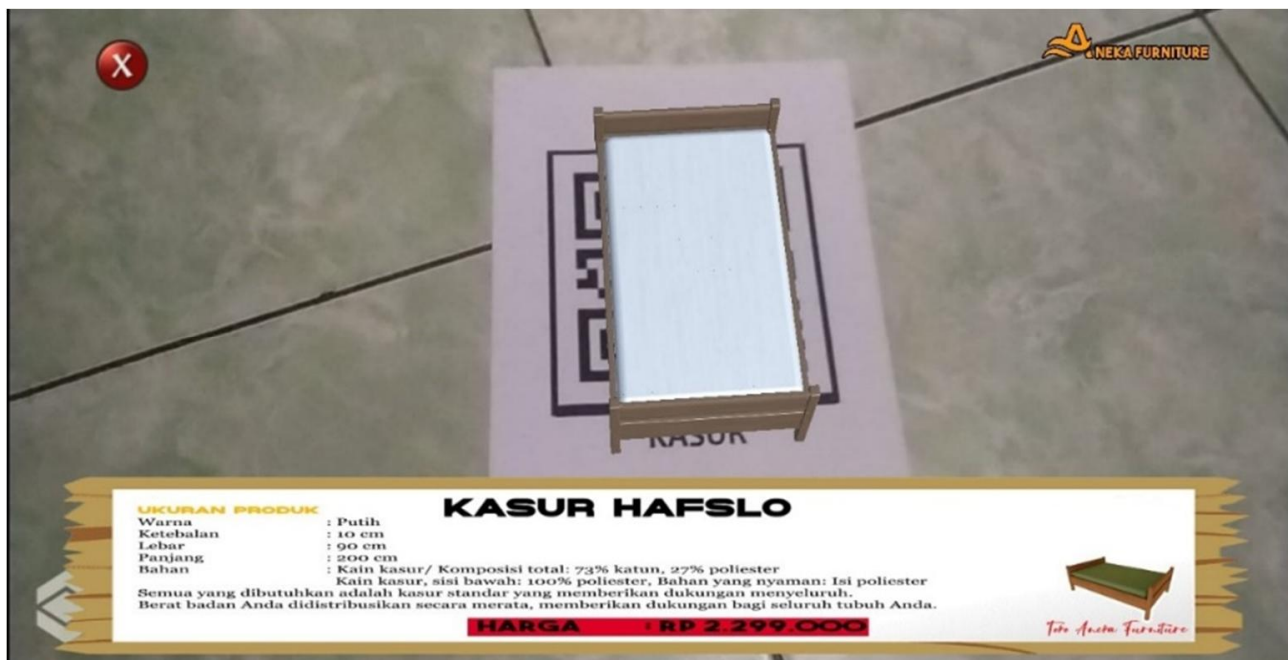

Gambar 18. Tampilan Objek Kasur

\subsection{Pengujian Aplikasi}

Dilakukan pengujian dengan perbedaan versi android. Pengujian berdasarkan jarak, kecepatan dan bias cahaya pada kamera yang mendeteksi marker.

1) Pengujian Versi Android

Pengujian menggunakan 2 perangkat yang berbeda dan versi android yang berbeda, untuk membandingkan kesesuaian pada aplikasi pada tiap device android yang digunakan. Pada tabel 2 adalah perangkat dan versi yang telah dilakukan pengujian.

Tabel 2 Pengujian Versi Android

\begin{tabular}{lc}
\hline \hline \multicolumn{1}{c}{ Perangkat } & Versi Android \\
\hline Realme 5i & 10 \\
Infinix Hot 9 & 9 \\
\hline
\end{tabular}

2) Pengujian Jarak

Pada hasil pengujian jarak yang dilakukan, terdapat jarak minimal dan jarak maksimal. Jarak minimal untuk mendeteksi marker pada smartphone Realme $5 \mathrm{i}$ adalah $\pm 12 \mathrm{~cm}$, dengan jarak maksimal $\pm 100 \mathrm{~cm}$. Dan pada smartphone Infinix, jarak minimal untuk mendeteksi marker adalah $\pm 12 \mathrm{~cm}$ dan jarak maksimal $\pm 100 \mathrm{~cm}$. Pada tabel 3 merupakan hasil pengujian jarak yang telah dilakukan.

Tabel 3. Hasil Jarak Pengujian

\begin{tabular}{lcc}
\hline \hline \multicolumn{1}{c}{ Perangkat } & Jarak Minimal & Jarak Maksimal \\
\hline Realme 5i & $\pm 12 \mathrm{~cm}$ & $\pm 100 \mathrm{~cm}$ \\
Infinix Hot 9 & $\pm 12 \mathrm{~cm}$ & $\pm 100 \mathrm{~cm}$ \\
\hline
\end{tabular}

3) Pengujian Waktu Respon

Pada pengujian waktu respon untuk menampilkan objek pada layar mempunyai perbedaan hasil pada smartphone yang digunakan. Dengan rata-rata waktu respon kurang dari 2 detik. Hasil pengujian terlihat pada tabel 4. 
Tabel 4. Hasil Pengujian Waktu Respon

\begin{tabular}{ll}
\hline \hline \multicolumn{1}{c}{ Perangkat } & Waktu Respon \\
\hline Realme $5 \mathrm{i}$ & 1,3 detik \\
Infinix Hot 9 & 1,6 detik \\
\hline
\end{tabular}

\section{KESIMPULAN} bahwa:

Berdasarkan hasil penelitian yang telah dilakukan penulis, maka dapat ditarik kesimpulan

1. Menghasilkan sebuah aplikasi Augmented Reality yang dibuat untuk memberi inovasi agar dapat dimanfaatkan dalam menarik daya beli pelanggan Toko Aneka Furniture dalam berbelanja.

2. Pengujian dengan menggunakan dua smartphone android. Yaitu Realme 5i dengan versi android 10, dapat disimpulkan bahwa jarak minimal untuk mendeteksi marker adalah $\pm 12 \mathrm{~cm}$ dan jarak maksimal untuk mendeteksi marker adalah $\pm 100 \mathrm{~cm}$. Dan pada Infinix Hot 9 dengan versi android 10, menunjukan jarak minimal untuk mendeteksi marker adalah \pm 12 , dan pada jarak maksimal adalah $\pm 100 \mathrm{~cm}$.

3. Algoritma Fast Corner Detection dan metode Marker Based Tracking digunakan dalam pembuatan aplikasi ini. Yang mana algoritma yang memanfaatkan titik sudut dengan nilai $P$ selaku titik pusat koordinat. Dan menggunakan metode Marker Based Tracking untuk mengenali dan menampilkan target dengan cara mengidentifikasi atau mengenali pola atau marker yang telah dibuat untuk menampilkan sebuah objek 3D ke ruang nyata.

4. Dalam pengujian waktu respon objek 3D muncul kurang dari 2 detik respon waktu yang dihasilkan.

\section{SARAN}

Terdapat beberapa saran pengembangan pada aplikasi, yaitu:

1. Menambah dan mengembangkan fitur-fitur agar menambah daya tarik, seperti animasi 3D, Video Promosi dan lain sebagainya.

2. Menambahkan fitur pembelian produk pada aplikasi.

\section{DAFTAR PUSTAKA}

[1] E. B. Sembiring, Sapriadi, and Y. C. Brahmana, "Rancang Bangun dan Analisis Aplikasi Augmented Reality pada Produk Furniture,” Integrasi, Vol. 8, No. 1, pp. 22-28, 2016, [Online]. Available: http://jurnal.polibatam.ac.id/index.php/JI/article/view/50.

[2] M. Dan, P. Cv, and J. Antique, "Gambar Marker Keterangan Meja Konsul Inggris desain Drawer Bombay Motif Lukisan Klasik Kepala Kijang Mangkok Buah Besar Meja Tempel Minimalis," Vol. 2, pp. 33-36, 2015, [Online]. Available: https://onesearch.id/Record/IOS2429.article-300/Details.

[3] A. T. Saputra and N. E. Budiyanto, "Penerapan Teknologi Augmented Reality Pada Katalog Mebel Kompas Jati Jepara Berbasis Android," J. Inform. dan Rekayasa 
Perangkat Lunak, Vol. 1, No. 2, pp. 82-87, 2019, doi: 10.36499/jinrpl.v1i2.2951.

[4] M. Jamal and A. Susanto, "Penerapan Teknologi Augmented Reality Sebagaimedia Promosi Berbasis Android," Univ. Dian Nusawantoro, pp. 1-8, 2012, [Online]. Available: http://eprints.dinus.ac.id/17027/.

[5] F. Al Rasyid, I. Fitri, and A. Andrianingsih, "Augmented Reality Katalog Penjualan IT Hardware Pada PT. Unibless Menggunakan Algoritma MSER (Maximally Stable Extermal Regions)," Smatika J., Vol. 10, No. 02, pp. 101-108, 2020, doi: 10.32664/smatika.v10i02.514.

[6] A. Junaidi, R. Prabowo, A. Syarif, and Y. Fazri, "Implementasi Augmented Reality Furniture Dengan User-Defined Target Berbasis Android,” J. Sist. Inf. Bisnis, Vol. 10, No. 1, pp. 64-72, 2020, doi: 10.21456/vol10iss1pp64-72.

[7] N. Wahyudi, R. A. Harianto, and E. Setyati, "Augmented Reality Marker Based Tracking Visualisasi Drawing 2D ke dalam Bentuk 3D dengan Metode FAST Corner Detection," J. Intell. Syst. Comput., Vol. 1, No. 1, pp. 9-18, 2019, [Online]. Available: https://jurnal.istts.ac.id/index.php/INSYST/article/view/28.

[8] agus A. Al Hakim Musthof, "Penerapan Teknologi Augmented Reality Pada Aplikasi Katalog Mebel Jepara Berbasis Android,” Semin. Nas. KMICE'08, Vol. IV, No. 1, pp. 1-30, 2017, [Online]. Available: https://www.cambridge.org/core/product/identifier/CBO9781107415324A009/type/book _part.

[9] B. Satria and P. Prihandoko, "Implementasi Metode Marker Based Tracking Pada Aplikasi Bangun Ruang Berbasis Augmented Reality," Sebatik, Vol. 19, No. 1, pp. 1-5, 2018, doi: 10.46984/sebatik.v19i1.88.

[10] K. Dohi et al., "Implementasi Teknologi Markerless Augmented Reality Menggunakan Metode Algoritma Fast Corner Detection Berbasis Android ( Studi Kasus Multimedia Buku Interaktif Kebudayaan Lokal Kalimantan Barat )," Coding J. Komput. dan Apl. ISSN 2338-493X, vol. 2018-Janua, No. August, pp. 1-4, 2019, [Online]. Available: https://jurnal.untan.ac.id/index.php/jcskommipa/article/view/30807.

[11] A. Arini and E. A. Fitrana, "Pengembangan Aplikasi Katalog Rumah Berbasis Augmented Reality Menggunakan Algoritma FAST,” JISKA (Jurnal Inform. Sunan Kalijaga), Vol. 4, No. 1, p. 9, 2019, doi: 10.14421/jiska.2019.41-02.

[12] G. Y. Abdillah, S. Andryana, and A. Iskandar, "Augmented Reality Sebagai Media Pembelajaran Perangkat Keras Komputer Dengan Fast Corner dan Natural Feature Tracking,” JIPI (Jurnal Ilm. Penelit. dan Pembelajaran Inform., Vol. 5, No. 2, p. 79, 2020, doi: 10.29100/jipi.v5i2.1767. 